Journal of Conservation Science

Vol.35, No.1, pp001-010(2019)

DOI https://doi.org/10.12654/JCS.2019.35.1.01

pISSN: $1225-5459$

Printed in the Republic of Korea

\title{
Studies on Sized Silks for East Asian Painting Background
}

\author{
Boyoung Lee ${ }^{1}$ | Hyo Seon Ryu* \\ Research Laboratory for Archaeology and History of Art, University of Oxford, OX1 3TG, UK \\ *Department of Textiles, Merchandising and Fashion design, Seoul National University, Seoul, 08826, Korea \\ ${ }^{1}$ Corresponding Author: bo0lee@outlook.com, +1-347-267-3655
}

\begin{abstract}
This study provides a comprehensive evaluation of general characteristics of sized silk fabrics for the painting purpose. Two particular types of silk fabrics used for painting background were compared: a recreation of historical material and a mass produced material of present day. The sizing process made the surface characteristics of the silk fabrics more suitable for painting. The dyeing properties of the fabrics were related to the surface area of the fabrics, and had no significant effect on their mechanical properties. The antibacterial activity of the tannin-based natural dyestuffs were maintained after the sizing. The performance assessment by the KES-FB system showed that the fabrics are more prone to deteriorate after the sizing because the glue layer receives the most of the physical stresses.
\end{abstract}

Key Words: Asian silk paintings, Sized silk, Handloom and powerloom, Tannin-based dyes, Fabric performance

\section{INTRODUCTION}

Kyujanggak Institute of Korean Studies is a national research institute, archives and museum affiliated to Seoul National University. This study was designed as a part of a joint research between Kyujanggak and Textile Science Laboratory(Department of Human Ecology, Seoul National University) as a preliminary investigation prior to the reproduction of a sixteenth-century cartography. During the process, we were able to conclude that several types of silks were used for cartographies and paintings in the archive. The majority of the silk fabrics used for the colour paintings have a particular structure that is not common in the clothing materials. Unfortunately, we also have found out the production of such type of silk fabrics are discontinued in Korea: the only commercially available type of painting silk is powerloom woven fabrics imported from China. As there was no study to provide scientific understandings regarding the silk painting grounds, a set of experiments to examine the characteristics of the particular type of silk fabric was implemented. By comparing the mechanical and chemical properties of the handloom woven fabrics and the commercial grade powerloom woven fabrics, we aimed to understand their characteristics and the suitability of these painting silk fabrics for the conservation and reproduction purposes.

\subsection{Silk as a painting ground}

Silk is one of the most common base materials of traditional East Asian paintings. It is seen particularly often in coloured paintings known as Chaesaekhwa(彩色畫). A tabby, or even a satin weave fabrics were found; however, a particular type of silk for paintings called Hwa-gyeon[畫絹 (China) / 絵絹(Japan)] seemed to be the most popular choice for a painting ground. On-line dictionary of Japanese architectural and art historical terminology(2014) defines 絵絹(Eginu) as the plain, non-glossy raw silk fabric that used for paintings. Hwa-gyeon has a special structure: there are 2 warp yarns as a set crossing over the weft, and there is a space between each set of warp yarns. It is similar to that of a gauze weave(紗). However, in the gauze weave, the 2 
warps cross over diagonally; whereas in Hwa-gyeon they maintain their original position and only move up and down over the weft(Figure 1). There are few variations in this modified tabby weave: 1) use the same yarns on both warp and weft-plain imitation gauze, 2) use a thicker yarn on the weft, 3 ) or use the same yarn but place 2 or more ply on the weft.

Hwa-gyeon, being thin and loosely woven, creates some degree of translucence: such characteristic distinguishes it from papers and other dense materials. There are both aesthetical and technical reasons behind the use of such an open structure for paintings: its suitability for the reverseside colouring technique called Baechae(背彩). For this technique, the silk fabrics must undergo a special process called Agyo-po-su(阿膠泡水), which means sizing: it is the application of glue and alum mixture solution. Once the glue is dried, it builds the body to the fabric and make it into a film-like material, and creates a suitable surface to paint. Hwa-gyeon, in general, is made of raw silk threads so that the thin threads would stand the high pressure in the weaving process. Due to their sericin-covered surface, they would have less affinity to the pigments than those of degummed silk fibres. Thus, once prepared, the silk for painting would have different properties from the clothing fabrics.

\subsection{Handloom vs. Powerloom woven silks}

The paintings and cartographies we examined are all pre-19th centuries, thus we could determine that the original background materials are all made woven from handlooms. Since the mechanical properties of this particular type of silk fabrics are unknown, we wanted to test its performances after the gluing process. However, it was difficult to secure

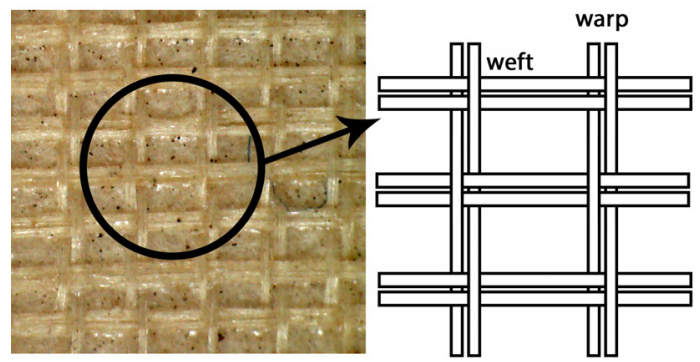

Figure 1. Typical appearance of Hwa-gyeon, a type of modified tabby weave. the sample materials: there was no clue left to find any commercially available handloom-woven painting silk, thus we commissioned one of the traditional weavers the production of close-to-the average material. According to 'The tradition and its succession of Japanese paintings', the power-loom woven silks are made under the hard tension thus have more uniformity and thread count(Tokyo Art University Department of Heritage Conservation Japanese Painting Laboratory, 2005). On the other hand, in handloom the weft would receive less tension than in power-loom, thus the fabrics would have more openly and loosely woven and suitable for the reverse colouring technique(Baechae) (Ryu and Lee, 2015). This implies that the power-loom woven fabrics would shrink more than the handloom woven fabric when wet.

The above-mentioned book also describes the vegetable dyeing of fabrics to match the background colour for the reproduction or conservation. It is not known whether our ancestors have the painting silks dyed, but the use of dyed papers to protect books against insect attacks suggests that the dyeing of silks might have been practised too. At present, silk fabrics are often dyed to light brown to match the colour of aged silk for conservation treatment or for reproduction. A key to this process is to choose appropriate dyestuffs that are both lightfast and capable of being dyed without a mordant because mordanting would adversely affect the stability of the silk. Thus in the last chapter of this research, we also examined the dyeability and antifungal activity of the painting silks, before and after the dyeing with selected vegetable dyes: Alnus japonica fruits, gallnut and cinnamon. These dyestuffs yield brownish yellow shades, and are commonly used in conservation treatment in Korea, China and Japan. The major colorant is hydrolysable tannin, and it is known to have a good affinity for silk. Cinnamon is also a tannin-based dye of brownish yellow shades that is much easier to source than $A$. japonica fruits and gallnut, for its popular use in home remedies and culinary. These dyes are well known to the public in Asia for their good antifungal properties. 


\section{EXPERIMENTAL}

\subsection{Sample preparation}

The characteristics of the silk fabrics are as described below(Table 1). Two different types of painting silks were prepared: one woven with handloom and the other woven with powerloom. The handloom woven silk was order-made by the hand of a skilled artisan, based on the design that imitates the average structure of the silks used in Kyujanggak's artefacts(Ryu and Lee, 2015). The powerloom woven silk was selected from a range of painting silks commonly used in conservation studios, based on its structure; it was manufactured in China.

\subsection{Shrinkage}

Silk pieces cut to $30 \mathrm{~cm} \times 30 \mathrm{~cm}$ were soaked in distilled water for 1 hour at $60^{\circ} \mathrm{C}$ to wash off the starch; then rinsed well with running distilled water and flat-dried. The shrinkage factor $(x)$ was measured by the following formula:

$A_{1}=$ Original area of the sample fabric before the treatment

$\mathrm{A}_{2}=$ Area of the sample fabric after the treatment(dried)

\subsection{Dyeing}

Dye extracts were made from dried vegetable dyes, and concentrated using a vacuum distillation apparatus. The absorption level of the dye extracts was adjusted to the same level(absorbance unit: 0.6 ) by the calculation of standard calibration curves. Then silk fabrics were completely immersed in a dye bath at $60^{\circ} \mathrm{C}$ for 20 minutes in a $1: 250$ liquor ratio. The temperature was fixed to $60^{\circ} \mathrm{C}$ to avoid the instability that often appears at higher temperatures in natural dyeing processes(Bae, 2002). Dyeing time was fixed to 20 minutes because the longer silk stays in a warm bath, the greater is the chance of losing sericin(Zhu et al., 1996). The acidity of the extracts were measured by $\mathrm{pH}$ electrode (HI8314, Hanna, USA)

The dyeability was examined by UV-VIS analysis of the dye bath to determine the dye adsorption rate, and compared to the characterisation of appearance in dyed samples based on CIE L*a*b* colour space and the K/S values(KubelkaMunk's formula) measured by the spectrophotometer (2600-d, Minolta, Japan), at reflectance range of 400 700 nm:

Table 1. Characteristics of the silk fabrics

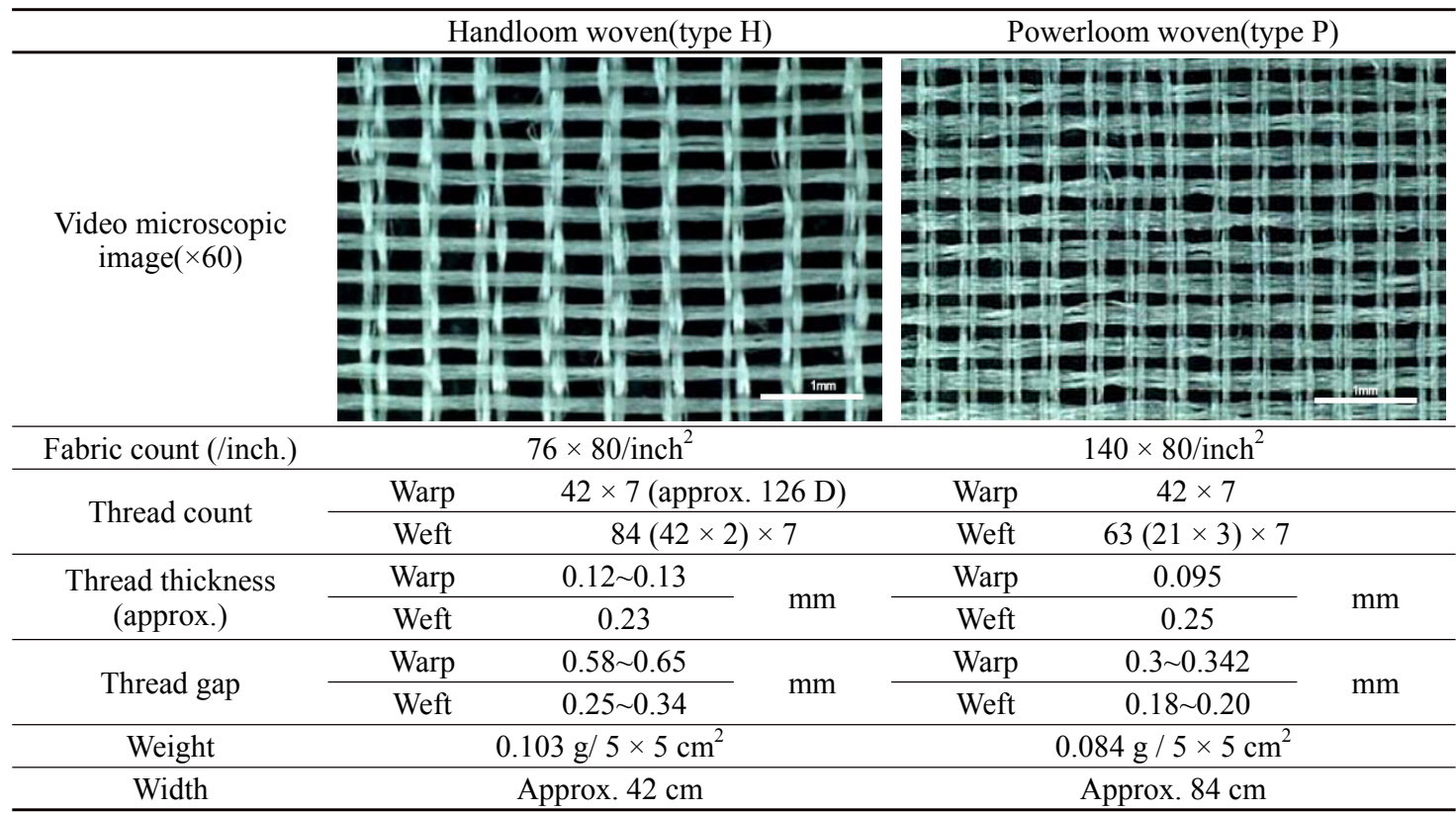


$\mathrm{K} / \mathrm{S}=\mathrm{R}(\lambda)=$ reflectance(at wavelength $\lambda)$

$\mathrm{K}=$ absorption coefficient

$\mathrm{S}=$ scattering coefficient

$\mathrm{C}=$ concentration of the absorbing species

$\mathrm{A}=$ absorbance

\subsection{Sizing}

The glue solution was prepared with $4 \%$ gelatine made from animal skins(Nakagawa Houou 39705, Japan) and $0.35 \%$ alum. Each sheet of silk was fixed on a frame, and then a thin layer of the glue solution was applied to the surface by the hands of skilled painting conservators. One cycle of application consisted of four steps: paint the front, dry in the open air, paint the reverse, and dry again in the open air. Each sample went through two cycles of glue application.

\subsection{Environmental control}

Samples were stored and tested in a controlled environment that is similar to the standard museum environment. The samples were tested and stored at the temperature between $18-21^{\circ} \mathrm{C}$ with $\mathrm{RH}$ below $65 \%$, avoiding light and pollution with less than $8 \mathrm{hrs}$ of light exposure/day( 200 lux)(Minnesota Historical Society, 1999).

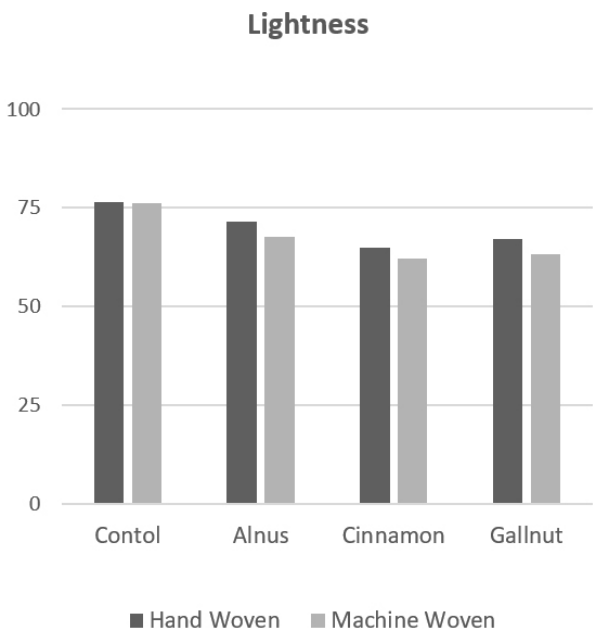

\subsection{Mechanical properties}

The tensile strength, shearing and surface properties after both dyeing and gluing were measured by the KESFB(Kawabata) system No.1 to 4, which are a set of objective methods to examine fabric handling properties at a micro scale. The surface of the samples before and after the gluing was captured with both video microscope and scanning electron microscopy(SEM).

\subsection{Antibacterial activity}

The assessment procedures followed the agar diffusion plate test of International standard(ISO 90645:2010, 2010), Textiles: Determination of antibacterial activity.

\section{RESULTS AND DISCUSSION}

\section{1. $\mathrm{pH}$, shrinkage and dyeing properties}

The $\mathrm{pH}$ of dye extracts was sub-acid; however, it did not affect the acidity of fabrics. The gallnut extract was $\mathrm{pH}$ of 3.9; A. Japonica extract was $\mathrm{pH} 5$; the cinnamon extract was $\mathrm{pH}$ 5.5. These would not affect the dissolution of sericin. Morover, the $\mathrm{pH}$ of the silk samples remained at 6.5-6.6 after the dyeing and sizing. There was no significant

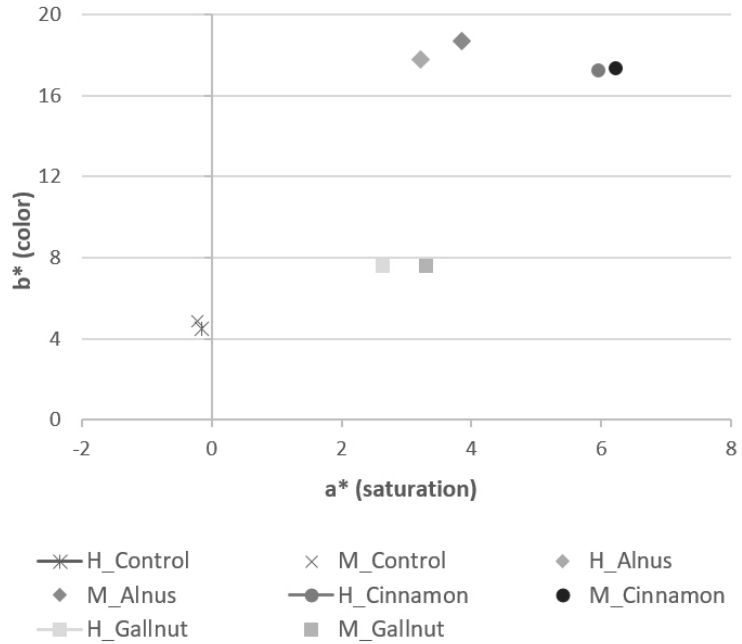

Figure 2. $\mathrm{L}^{*} \mathrm{a} * \mathrm{~b} *$ index of dyed samples $(\lambda \max =420 \mathrm{~nm})$. 
difference in the shrinkage rates of the samples after dyeing, in both handloom woven(type $\mathrm{H}$ ) and powerloom woven(type P) painting silks. The degree of shrinkage was bigger in the dyed samples than undyed samples: it is thought to be affected by the physical stimulation during the dyeing process that have facilitated the movement of the yarns.

Regardless of the type of silks, all samples have maintained their original width through the wetting and drying, but the lengthwise shrinkage were $4 \%$ in control, and $7 \%$ in coloured samples. In hypothesis, the type P would shrink more than the type H. However, there was no significant difference between the two. It could have resulted from the higher number of fabric count of the type $\mathrm{P}$, which indicates there was less space for the yarns to move, or from the difference in the degree of degumming. These two fabrics have the same warp fabric count, and the type $\mathrm{P}$ has almost as twice as much warp fabric count. Assume that they are made with the same yarn, the type $\mathrm{P}$ is supposed be weight $10 \%$ more than the type $\mathrm{H}$. However, the type $\mathrm{H}$ was actually $20 \%$ heavier in weights than the type P. Such difference is most likely because of the lighter weight of the yarns used in the type P: if the yarns used for the type $\mathrm{P}$ were more degummed than those used for the type $\mathrm{H}$, the type $\mathrm{P}$ would less likely to shrink by the boiling water.

In the colour analysis, $A$. Japonica showed the highest $\mathrm{L}^{*}$ value, gallnut and then cinnamon followed. On the $\mathrm{a}^{*}$ and the $\mathrm{b}^{*}$ axis, A. Japonica appeared in a yellowish-brown colour, the cinnamon appeared in a reddish-brown colour, and the gallnut appeared in a pale brown colour(Figure 2). This indicates that it is possible to choose a specific type of dye matter when it is necessary to match certain shades. See the comparison of the test samples and the paintings from 1400s-1900s(Figure 3).

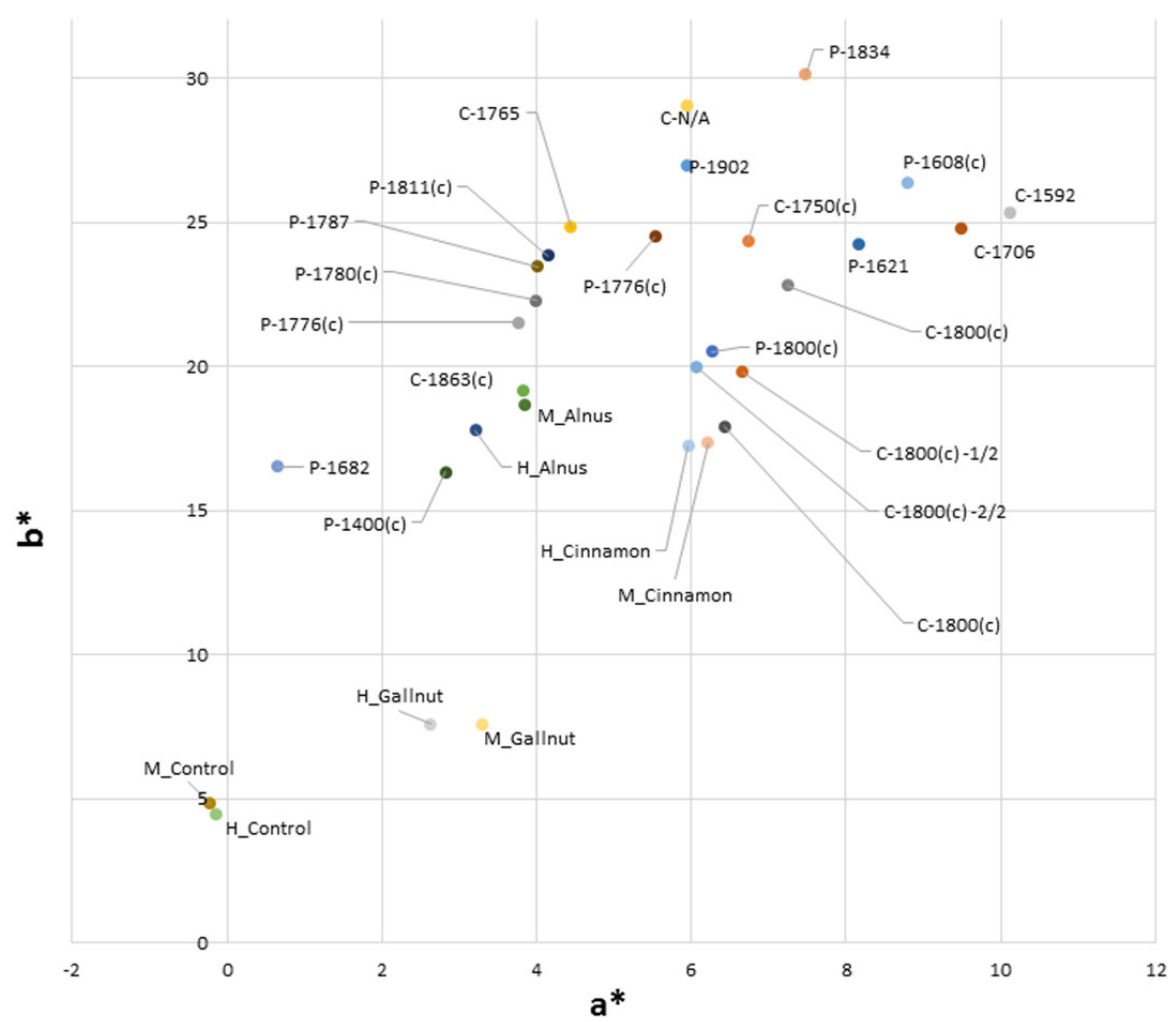

Figure 3. CIE a*, b* index of the samples in comparison with the group of artefacts(painted on the modified tabby weave silk fabrics). 
The K/S values were higher in the order of cinnamon, gallnut and A. Japonica: judging by the CIE L* value and $\mathrm{K} / \mathrm{S}$ value in comparison, cinnamon had the best dyeing efficiency and the A. Japonica had the least when applied at the same AU. There was no significant difference between the handloom-woven and power loom-woven silks, but the former showed a slightly lighter colour and thus the lower $\mathrm{K} / \mathrm{S}$ value.

\subsection{Mechanical properties}

It is easy to infer the role of sizing in the preparation of silk painting ground; however, there has been no scientific interpretation of it. To achieve that, the silk samples were prepared as in the process of traditional painting preparation and observed by SEM imaging $(\times 300)$, both control and test specimens dyed with three different natural antibacterial dyes. Then the samples were tested by subjective evaluation systems of mechanical properties of textiles developed by Kawabata(1980). Kawabata Evaluation System(KES) for fabrics(FB) offers a set of simulations of physical stresses that can be imposed on fabrics in general use. The purpose of KES-FB tests is to examine the changes in physical properties of silk fabrics once sized and then stressed

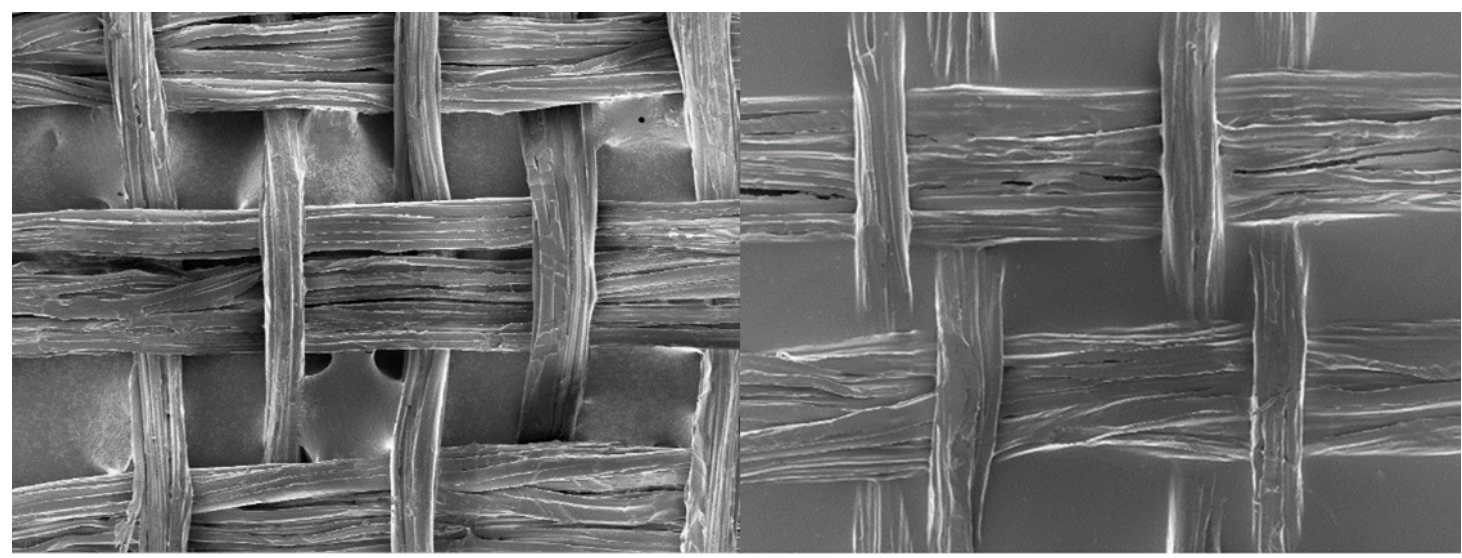

Figure 4. FE-SEM images of the samples before/after gluing $(\times 300)$.

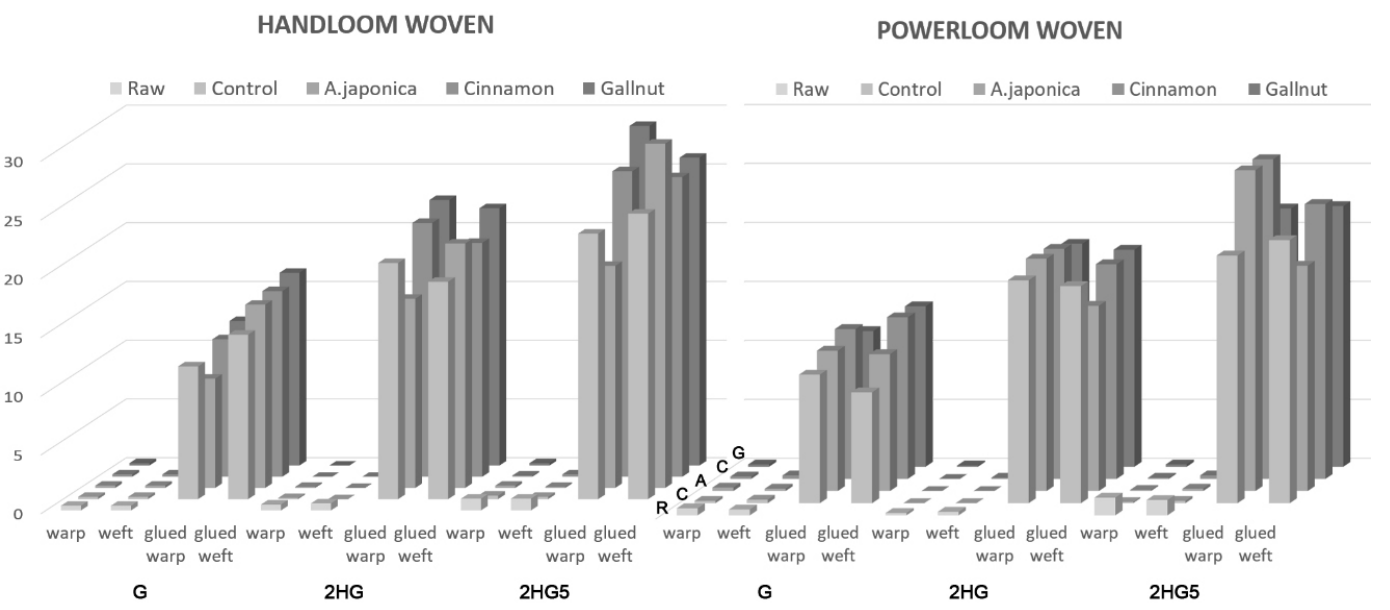

Figure 5. Shear properties(rigidity and hysteresis) of the samples $(\mathrm{G}, 2 \mathrm{HG}, 2 \mathrm{HG} 5)$ : shear rigidity indicates the average slope of linear regions of the shear hysteresis look at $\pm 0.5^{\circ}$ of shear angle; shear hysteresis indicates the hysteresis of shear force at $0.5^{\circ}(2 \mathrm{HG})$ or $5^{\circ}(2 \mathrm{HG} 5)$. 
during the handling and display.

The protein glue used in sizing formed a film-like thin transparent layer that almost completely fills up the gaps between the threads of modified tabby weave(Figure 4). This improved the surface property, to be more even and capable of holding the pigments, and the stability of the structure against the tensile, shearing, and bending tests.

\subsubsection{KES-FB 1 for 0 : shear stiffness; for 1: tensile}

Shear Rigidity $(\mathrm{G}: \mathrm{N} / \mathrm{m})$ and Shear Hysteresis (2HG, 2HG5: $\mathrm{gf} / \mathrm{cm}$ ) values were all increased by sizing. In sum, the amount of shear strain recovery was dropped and the silk fabrics became more rigid. This indicates that the fabrics are more stable against the low-intensity physical stimulations, such as brush strokes, and sizing helps the fabrics to stay in place and do not shear along the forces given during the painting works(Figure 5).

The extension properties of the fabrics were all increased after the sizing: the increment was larger in warp than in weft, and in handloom-woven fabric than in power loom-woven fabric. This indicates that there was less tension put upon the warp threads, which is consistent with the open arrangement of warps in the modified tabby weaves. And also, this proves the handloom creates more loosely tensioned fabrics than the powerloom does(Figure 6).

\section{HANDLOOM WOVEN}

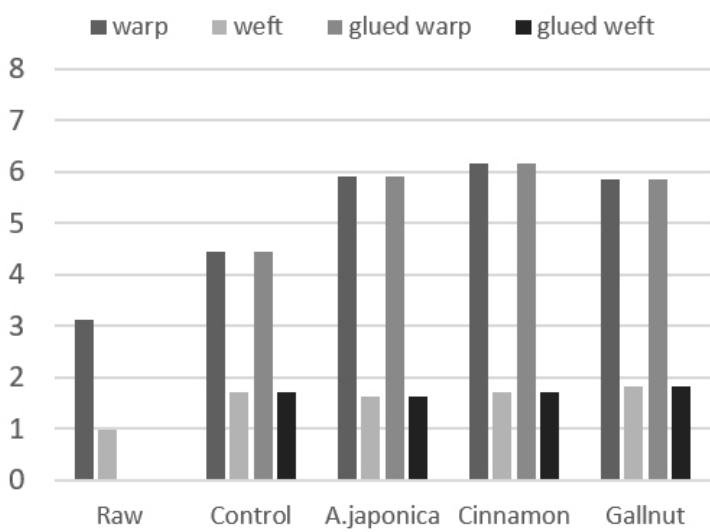

\section{POWERLOOM WOVEN}

warp weft alued warp

glued weft

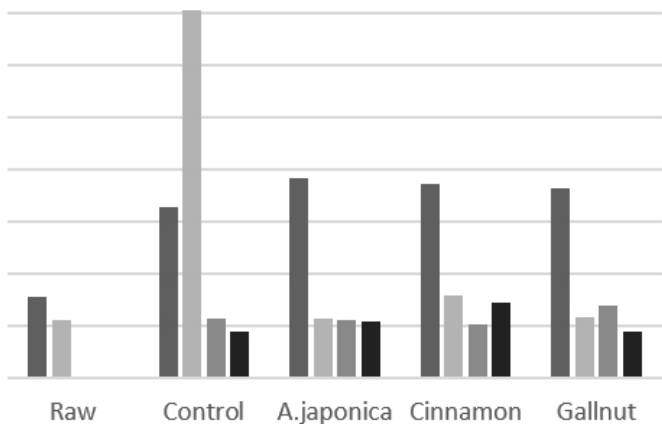

Figure 6. Tensile property-EMT (\% of extension at maximum applied load of $500 \mathrm{~g} / \mathrm{cm}$ ).

HANDLOOM WOVEN

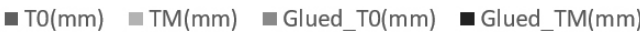

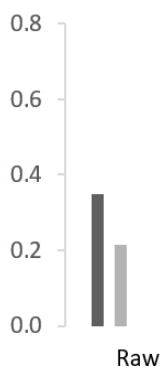

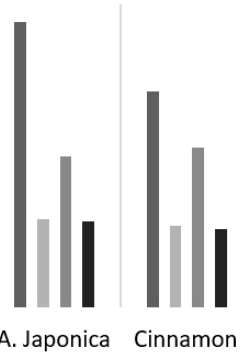

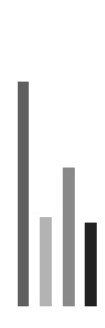

POWERLOOM WOVEN

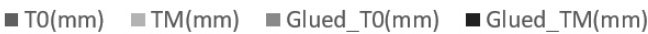

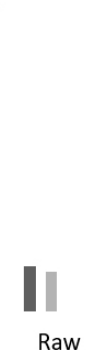

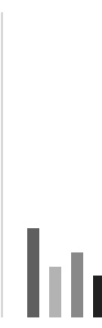

Control

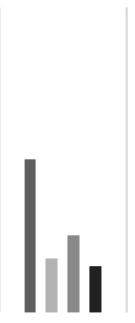

A. Japonica

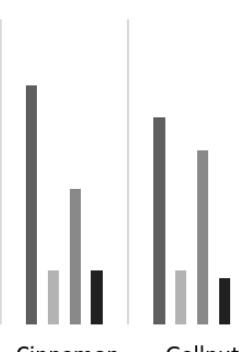

Figure 7. Compression characteristic of the samples. 


\subsubsection{KES-FB 2 for compression}

There was a slight increment of fabric thickness after the immersion in water and dyeing, and also a decrement after the sizing. This indicates the fibres once loosened by the moisture were compressed again by the sizing(Figure 7).

\subsubsection{KES-FB 3 for bending rigidity}

The bending rigidity(B) $\left(\mathrm{g} . \mathrm{cm}^{2} / \mathrm{cm}\right)$ of the samples was largely increased by the sizing. In other words, the sizing made the fabrics stiffer and thus more physical force is required to bend the samples to a certain degree. In Kim and Ryu(2010), the denser the fabric the value of bending property was higher. Thus it is assumed that the bending property value was increased as the thin layer of glue filled up the spaces between the threads and made the fabric denser(Figure 8).

HANDLOOM WOVEN

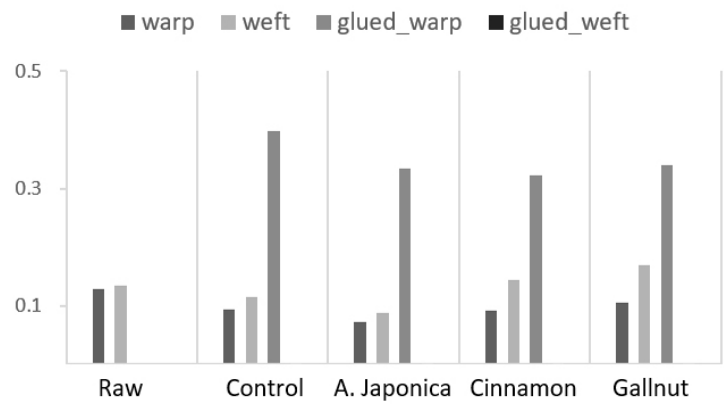

Figure 8. Bending rigidity(B) of the samples.

HAND WOVEN

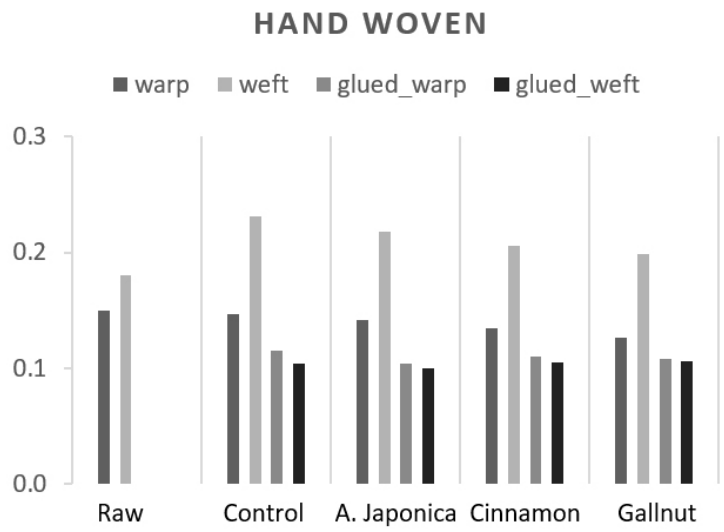

3.2.4. KES-FB 4 for surface property

This measures the surface friction and roughness of the fabric. The coefficient of friction(MIU, 0 to 1 with a higher value corresponding to greater friction or resistance and drag) value was once increased after the dyeing, then decreased after the sizing. The increment after the dyeing is in accordance to the result of Kim and Ryu(2010): MIU would increase after dyeing because the surface of silk would become rougher once sericin was partially removed during the dyeing process. This also explains the decrement of the value after sizing, for its surface-coating effect(Figure 9).

\subsection{Antibacterial activity of natural dyes}

In the test of anti-bacterial properties, only the gallnut dyed samples showed a superior result, in both hand and
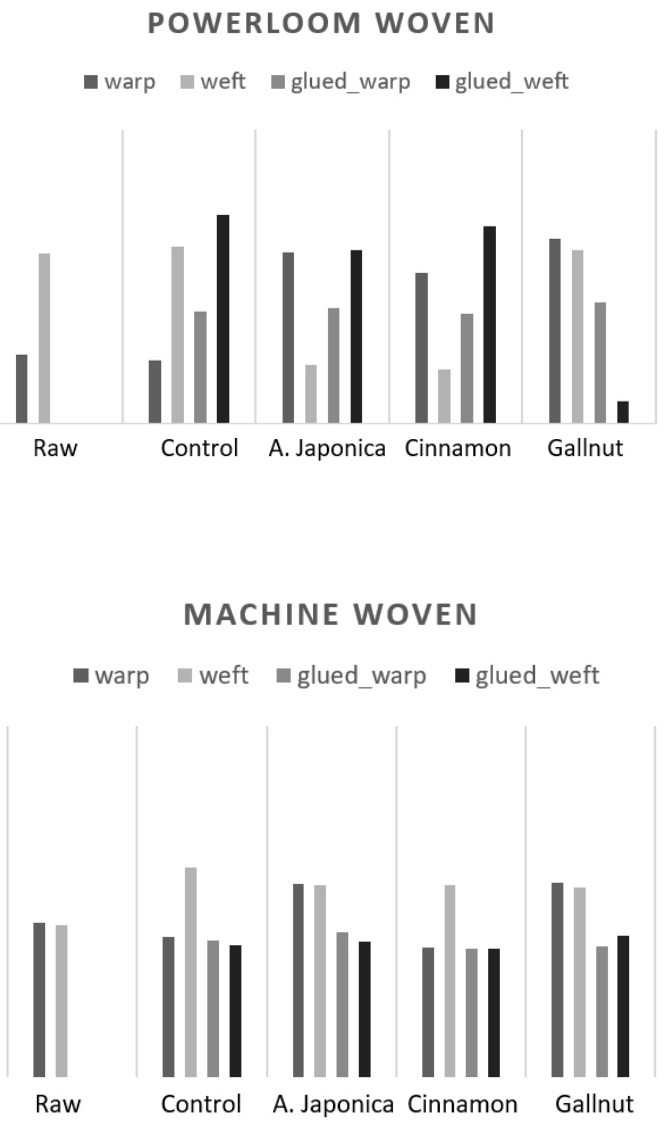

Figure 9. Surface property of the samples-MIU(coefficient of friction). 
power loom woven silks. However, when sized, only the power loom-woven silk maintained such antibacterial activity(Table 2). A previous study using the same dyes on thin clothing silk fabrics under the similar condition indicated that all these dyes successfully enhance the antibacterial properties of the fabrics(Yoon, 2014); this could have resulted from the smaller surface area due to the loose structure, thus less adsorption of active ingredients occurred. Alternatively, the application of animal protein glue that forms a layer over the fibre surface could have retarded the release of antibacterial substances. In theory, the gallotannins in gallnut would have a better efficacy against the test strains than the other types of tannins in $A$. Japonica and cinnamon(hydrolysable/condensed). It is also possible that the different level of tannin contents in each dye could have affected the result; however, further studies using a higher concentration of dye extracts would be necessary to support this discussion.

\section{CONCLUSION}

A set of experiments to compare the performances of the handloom woven and the powerloom woven silk fabrics as a painting background were implemented. There was no significant difference between the two types of silk fabrics, except some minor differences in dyeing and mechanical properties: the handloom woven fabrics showed less shrinkage rate than the powerloom woven fabric; the powerloom woven fabrics showed higher dyeability than the handloom woven fabric. This has resulted from the difference in surface area, which is related the difference in fabric counts(density). Although the use of natural dyes also did not affect the mechanical properties of fabrics, the higher dyeability of power loom woven fabrics also resulted in better performance in antibacterial efficiency test when both types of fabrics were dyed with gallnut-a tannin-rich natural brown dyes. Thus, technically, there is

Table 2. Antibacterial efficiency of each sample-resistance to bacterial attack

\begin{tabular}{|c|c|c|c|c|c|c|c|}
\hline & & \multicolumn{3}{|c|}{ Strain 1} & \multicolumn{3}{|c|}{ Strain 2} \\
\hline & & $\begin{array}{c}\text { Inhibition } \\
\text { zone }\end{array}$ & Growth & Determination & $\begin{array}{c}\text { Inhibition } \\
\text { zone }\end{array}$ & Growth & Determination \\
\hline \multirow{8}{*}{$\begin{array}{c}\text { Handloom } \\
\text { woven }\end{array}$} & Control & 0 & Moderate & Insufficient & 0 & Moderate & Insufficient \\
\hline & (Sized) & 0 & Moderate & Insufficient & 0 & Moderate & Insufficient \\
\hline & A. Japonica & 0 & Moderate & Insufficient & 0 & Moderate & Insufficient \\
\hline & (Sized) & 0 & Moderate & Insufficient & 0 & Moderate & Insufficient \\
\hline & Cinnamon & 0 & Moderate & Insufficient & 0 & Moderate & Insufficient \\
\hline & (Sized) & 0 & Moderate & Insufficient & 0 & Moderate & Insufficient \\
\hline & Gallnut & 1.0 & None & Good effect & 1.0 & None & Good effect \\
\hline & (Sized) & 0 & Moderate & Insufficient & 0 & Moderate & Insufficient \\
\hline \multirow{8}{*}{$\begin{array}{c}\text { Powerloom } \\
\text { woven }\end{array}$} & Control & 0 & Moderate & Insufficient & 0 & Moderate & Insufficient \\
\hline & (Sized) & 0 & Moderate & Insufficient & 0 & Moderate & Insufficient \\
\hline & A. Japonica & 0 & Moderate & Insufficient & 0 & Moderate & Insufficient \\
\hline & (Sized) & 0 & Moderate & Insufficient & 0 & Moderate & Insufficient \\
\hline & Cinnamon & 0 & Moderate & Insufficient & 0 & Moderate & Insufficient \\
\hline & (Sized) & 0 & Moderate & Insufficient & 0 & Moderate & Insufficient \\
\hline & Gallnut & 1.0 & None & Good effect & 1.0 & None & Good effect \\
\hline & (Sized) & 0 & None & Good effect & 1.0 & None & Good effect \\
\hline
\end{tabular}

Inhibition zone: Average value ( $\mathrm{mm}$ )

Growth: Bacterial growth on Trypticase Soy media under test fabric

Strain: 1. Staphylococcus aureus ATCC 6538

2. Klebsiella pneumoniae ATCC 4352 
no disadvantage of using powerloom woven fabrics than handloom woven fabrics. However, the differences in weaving density result in noticeably different impressions when applied in the making of a replica or in the conservation of existing artworks. The choice of the painting ground fabrics is entirely left to the hands of conservators, depending upon their aesthetical or economical preference. For a better future resourcing of the close-tooriginal material, it is highly recommended to secure the production of handloom woven fabric. Otherwise, the weaving design in the power loom must be improved to imitate the handloom woven fabric structure.

The sizing process affects the physical properties of silk fabrics. It creates a thin layer of transparent film over the surface: the glue fills the blank spaces and re-organising the structure of the fabric suitable for the reverse colouring. The transparent area would be larger in the loosely woven fabric, thus the more translucent impression the painting would yield. However, the sizing increased the bending rigidity and shearing properties of fabrics. In other words, the sized silk fabrics are more suitable for the painting, however weaker to the physical stresses such as bending and folding. The SEM images of the specimens after the mechanical tests would give us an insight into what happens to the paintings under the physical stresses. This result leaves us a question about the safety of the long tradition of scrolling the paintings for storage. If the space allows, it is recommended to keep the sized-silk based artefacts flat-laid.

It is hoped that the results of this study would give an idea to the better selection of conservation and replication material and methods, as well as to the display and storage of silk-based traditional paintings.

\section{REFERENCES}

Bae, H.S., 2002, Study on the dyeability, antibacterial and deodorization activities of extracts from Coptis chinensis Franch by electrolytic water. Ph.D. dissertation, Keimyung University, Daegu, 10-36. (in Korean with English abstract) ISO 90645:2010, 2010, Textiles: Determination of antibacterial activity.

Kawabata, S., 1980, The standardization and analysis of hand evaluation, 2nd. Ed. The Hand Evaluation and Standardization committee. Textile Machinery Society of Japan, Osaka.

Kim, H.A. and Ryu, H.S., 2010, Objective hand of highperformance silk fabrics. Journal of the Korean Society of Clothing and Textiles, 34(5), 754-764.

Minnesota Historical Society, 1999, Environment test kit manual. Saint Paul: Conservation Outreach Program.

On-line dictionary of Japanese architectural and art historical terminology, 2014, Japanese architecture and art net users system. http://www.aisf.or.jp/ jaanus/deta/e/eginu.htm(July $10,2014)$

Ryu, H.S. and Lee, B.Y., 2015, A scientific study on fibres and organic materials of Kyujanggak's artifacts. The Korean Costumes, 34, 41-72.

Tokyo Art University Department of Heritage Conservation Japanese Painting Laboratory, 2005. The illustrated tradition and succession of the Japanese painting. Tokyo Art, Tokyo, 15-46 (in Japanese)

Yoon, S.H., 2014, Dyeing properties and antibacterial activity of natural brown dyes on silk. Master's thesis, Seoul National University, Seoul, 1-25. (in Korean with English abstract)

Zhu, L.J., Arai, M. and Hirabayashi, K., 1996, Sol-gel transition of sericin. Journal of Sericultural Science, 65(4), 270-274. (In Japanese) 